\title{
Supporting laparoscopic general surgery training with digital technology: The United Kingdom and Ireland paradigm
}

\author{
Gemma Humm ${ }^{1,2^{*}} \mathbb{D}$, Rhiannon L. Harries ${ }^{3}$, Danail Stoyanov ${ }^{1,4}$ and Laurence B. Lovat ${ }^{1,2}$
}

\begin{abstract}
Surgical training in the UK and Ireland has faced challenges following the implementation of the European Working Time Directive and postgraduate training reform. The health services are undergoing a digital transformation; digital technology is remodelling the delivery of surgical care and surgical training. This review aims to critically evaluate key issues in laparoscopic general surgical training and the digital technology such as virtual and augmented reality, telementoring and automated workflow analysis and surgical skills assessment. We include pre-clinical, proof of concept research and commercial systems that are being developed to provide solutions. Digital surgical technology is evolving through interdisciplinary collaboration to provide widespread access to high-quality laparoscopic general surgery training and assessment. In the future this could lead to integrated, context-aware systems that support surgical teams in providing safer surgical care.
\end{abstract}

Keywords: Surgical training, Digital technology, Laparoscopic surgery, Simulation, Virtual reality mobile application, Artificial intelligence, Nontechnical skills, Telementoring

\section{Background}

The health services in the United Kingdom and Ireland are undergoing a digital transformation $[1,2]$. This has been mandated by the National Health Service (NHS) Long Term Plan and is supported by an additional $£ 4.8$ billion of Government investment in 2020-21 [3]. There is considerable support for the digitisation of the health services and the training of heath care professionals [4, 5]. Preparing the workforce for the changes in digital healthcare and training requires an infrastructure that facilitates multidisciplinary, collaborative work-placed learning with digital literacy incorporated into training [4]. Across surgical specialties, there is strong emphasis on surgical training and the development of innovate

\footnotetext{
*Correspondence: g.humm@ucl.ac.uk

${ }^{1}$ Wellcome/EPSRC Centre for Interventional and Surgical Sciences, University College London, Charles Bell House, 43-45 Foley Street, London W1W 7TY, UK

Full list of author information is available at the end of the article
}

digital training in minimally invasive surgery [5]. Collaboration between surgical, engineering and computer science disciplines is crucial to ensuring the most critical issues will be addressed using innovative technology. Empowering surgeons to integrate technology into their roles could promote new concepts and the development and validation of new technologies, which can be facilitated by early adoption of technology into training, flexible surgical training and diverse Out of Program experiences $[4,5]$.

Surgical training in the UK and Ireland is overseen by the Joint Committee on Surgical Training (JCST) and the Surgical Royal Colleges for all surgical specialties. Training in General Surgery is a 6-year full time Specialty Training program which can be entered after passing the Intercollegiate Membership of the Royal College of Surgeons Exam and satisfactory completion of the Core Surgery (or equivalent) program. General Surgery trainees graduate from their program with a Certificate of Completion of Training (CCT) in General Surgery 
with a special interest. Table 1 summarises general surgical trainee operative experience requirements and index procedures that can be undertaken laparoscopically, training benchmarks indicate the stages of training that one would be expected to undertake cases related to special interest training [6-9]. Surgical training is undergoing a period of transition, with the introduction of an updated, competency-based curriculum (rather than time-based) which continues to support simulation training and should offer surgical trainees more flexibility in their training experiences [8-10].

This review aims to identify issues facing surgical training and appraise the evidence of digital technologies that may support and facilitate laparoscopic general surgical training.

\section{Surgical training and laparoscopic general surgery Training opportunities}

The implementation of European Working Time Directive (EWTD) and postgraduate reforms has reduced training time and operative experience. A comparison of 154 general surgical trainees' logbooks was made in the first six months of implementation in August 2004 with the corresponding six months in 2003. Across the UK a $15.5 \%$ reduction in the overall logged cases was demonstrated [11]. Trainees reported an $11 \%$ and $18 \%$ reduction in coloproctology and upper gastrointestinal (UGI) surgery experience, respectively and an overall reduction index general surgery cases of $21 \%$ [11]. However, there is no literature detailing the specialist interest, or laparoscopic surgery logbook analysis. This is likely a reflection of the more generalised training received by trainees in the years before EWTD and the increase in special interest, centralisation and laparoscopic cases in the latter years. In another study, two surgeons' operative were compared, demonstrating reductions in experience at "senior house officer" (SHO), approximately equivalent to core surgical training, level in both elective and emergency cases [12]. Surgeon A, reported working $100-120 \mathrm{~h}$ per week during a 12-month general surgery post in 1985-87, performed 35 elective inguinal hernia repairs, elective 22 cholecystectomies, 70 appendicectomies and 9 emergency laparotomies under supervision. Surgeon B, reported working approximately $48 \mathrm{~h}$

Table 1 Summary of potential laparoscopic operative experience required through general surgery training [6-10] adapted from 2017 and 2021 core surgery and general surgery curricula

\begin{tabular}{|c|c|c|c|c|c|c|c|c|c|}
\hline & \multicolumn{3}{|l|}{ ST3/Phase 2 Entry } & \multicolumn{2}{|c|}{ ST4 benchmark } & \multicolumn{2}{|c|}{$\begin{array}{l}\text { ST6/Phase } 3 \text { Entry } \\
\text { benchmark }\end{array}$} & \multicolumn{2}{|l|}{$\mathrm{CCT}$} \\
\hline & & Level $^{c}$ & Number ${ }^{d}$ & Level $^{c}$ & Number $^{d}$ & Level $^{c}$ & Number ${ }^{d}$ & Level $^{c}$ & Number $^{d}$ \\
\hline & $\begin{array}{l}\text { Coordination of camera and instruments } \\
\text { from a } 2 \text { D display during surgical endos- } \\
\text { copy }\end{array}$ & 2 & - & - & - & - & - & - & - \\
\hline & Placement of laparoscopic ports & 1 & - & - & - & - & - & - & - \\
\hline & Procedures logged c & - & $>20$ & - & - & - & - & - & - \\
\hline \multirow{6}{*}{$\begin{array}{l}\text { Operative } \\
\text { experi- } \\
\text { ence }\end{array}$} & Appendicectomy & 2 & - & 3 & - & 3 & 70 & 4 & 80 \\
\hline & Inguinal Hernia & - & - & - & - & 4 & 50 & - & - \\
\hline & $\begin{array}{l}\text { Cholecystectomy } \\
\text { Cholecystectomy }\end{array}$ & $\begin{array}{l}- \\
-\end{array}$ & $\begin{array}{l}- \\
-\end{array}$ & $\begin{array}{l}2 \\
-\end{array}$ & $\begin{array}{l}- \\
-\end{array}$ & $\begin{array}{l}4 \\
4\end{array}$ & $\begin{array}{l}40 \\
60\end{array}$ & $\begin{array}{l}4 \\
4\end{array}$ & $\begin{array}{l}50 \\
110\end{array}$ \\
\hline & Anterior resection (high) & - & - & 1 & - & 2 & 5 & 4 & 30 \\
\hline & Segmental colectomy ${ }^{a}$ & - & - & 2 & - & 3 & 20 & 4 & 50 \\
\hline & $\begin{array}{l}\text { Major UGl procedures } \\
\text { - Liver resection } \\
\text {-Pancreatic } \\
\text { resection } \\
\text {-Oesophagectomy } \\
\text { - Gastrectomy } \\
\text {-Anti-reflux surgery }\end{array}$ & - & - & 2 & - & 2 & 10 & 3 & 35 \\
\hline
\end{tabular}

\footnotetext{
a Colorectal special interest trainees

b UGI special interest trainees who will concentrate on either oesophogastric or hepatopancreaticobilary procedures

c Competence levels 1 -Has observed, $2 a-$ Guidance required for most/all of the procedure (or part performed) $2 b$ Guidance or intervention required for key steps only $3 a$-Procedure performed with minimal guidance or intervention (needed occasional help) $3 b$-Procedure performed competently without guidance or intervention but lacked fluency 4 a- Procedure performed fluently without guidance or intervention $4 \mathrm{~b}-\mathrm{As} 4 \mathrm{a}$ and was able to anticipate, avoid and/or deal with common problems/complications

d No specific proportion of laparoscopic cases specified
} 
per week during 19 months general surgery experience in 2006-07, performed 6 elective inguinal hernia repairs, 1 elective cholecystectomy, 4 appendicectomies and 2 emergency laparotomies under supervision [12].

In Ireland surgical SHO operative experience data was collected prospectively over a 5-month period pre- and post-EWTD reduction in working hours [13]. Group 1 (August-December 2008) worked a median of $67 \mathrm{~h}$ per week (range 46-92), and Group 2 a median of $57 \mathrm{~h}$ per week (range 40-81). Total operative volume was reduced in Group 2 by $24 \%(\mathrm{p}=0.006)$. In Group 2, volume of cases assisted reduced by $26 \%(\mathrm{p}=0.005)$ and a reduction of $63 \%(\mathrm{p}=0.04)$, in intermediate cases (e.g., appendicectomy inguinal hernia repair) as primary operator but no reduction of minor cases (e.g. excision of skin lesion) as primary operator [13].

The reduction of surgical training opportunities has persisted. In 2017 a survey of 902 core surgical $0.3 \%$ of respondents' posts adhered to all JCST generic quality indicators [9]. In general surgery, a $18.9 \%$ adherence was reported to the quality indicators; "Attend three supervised operating sessions (one of which should be an emergency session)" and "two supervised outpatient clinics each week" [14]. Failure to achieve quality indicators may put trainees who continue to higher surgical training in an inferior position to their peers by training inequality. The impact of this may not be seen until these trainees enter their consultant years.

One potential solution to the reduction in operating exposure is simulation training. However, this is not without its challenges. In a 2018 survey of $86.2 \%$ of respondents wanted improved access to simulation training [15]. The survey results suggest there is regional variability in access to simulation training with $52.9 \%$ of respondents reported that there was access in their region. In one region, $27.3 \%$ of respondents reported no access to simulation training, in another region, $84 \%$ of respondents reported access at predetermined times. This survey identified that there may be inequitable access to simulation training, however, the nature of inequality is not explored and requires further research [15]. Delivering simulation training digitally could alleviate some inequality. Digital simulation could be delivered by devices that do not require dedicated laboratories and simulation teams to prepare and maintain or with portable devices that facilitate more flexible training in the hospital or at home.

\section{Virtual, augmented and mixed reality}

Virtual reality (VR) is an artificial environment which is experienced through sensory stimuli provided by a computer in which one's actions determine what happens in the environment [16]. VR in general surgery training can be in the form of in interactive digital platform accessed on a personal device [17] or a simulated laparoscopic operation with digital display and electronic sensors tracking instrument kinematics [18]. Different systems exist and can also include haptics [19] and immersive headsets [20].

A meta-analysis of randomized control trials (RCT) compared virtual reality (VR) simulation with either a box-trainer or no supplementary training in laparoscopic skills for junior trainees [21]. VR simulation significantly improved operative time and performance compared to no supplementary training or box-training [21]. Furthermore, structured surgical coaching was added to medical student training in VR laparoscopic cholecystectomy, comparing coaching plus instructional video with instructional video alone [22]. This RCT demonstrated the technical skills, assessed by blinded observers, using the Competency Assessment Tool (CAT) were consistently and significantly higher in the intervention group across multiple attempts with a significant reduction of errors and a plateau in the proficiency-gain curve of the intervention group [22].

Augmented and mixed reality describe systems whereby a virtual environment is overlayed and blended with the real environment [23], which can be viewed on immersive headsets. This technology has had limited use in simulating laparoscopic surgery, but is supporting the use of patient-specific anatomical models from preoperative imaging, to facilitate preoperative planning and training [24]. Operative guidance and navigation will require successful registration of images to patients, and is dependent on fixed anatomy and preferably with or within a bony frame [25]. As some abdominal organs are inherently mobile and move with pneumoperitoneum and ventilation, an environment which is not present during preoperative scanning, this technology may be less suited to laparoscopic abdominal surgery. Mixed reality and immersive headsets have been used during a case of robotic-assisted Transanal Total Mesorectal Excision of the rectum (TaTME). A trainee and assistant were able to view video feed from robotic (abdominal) camera and the endoscopic (rectal) camera in a single patient feasibility study where time worn was limited [26].

Another possible barrier to the use of this technology in laparoscopic surgery is that the operative field is visualised on a separate screen, and the axis is directed away from the patient. Using "see through" immersive headsets as an alternative means for the operating surgeon to view the endoscopic video has been used in cases of ureteroscopy $[27,28]$. In the simulated setting the mixed reality headset facilitated the simultaneous viewing of endoscopic video, preoperative imaging and fluoroscopy and was found to reduce operative time and OSATS 
scores [28]. At the time of writing there were no published studies of a similar use of immersive headsets in laparoscopic abdominal/pelvic surgery. Augmented reality laparoscopic surgical navigation is likely to improve with systems whereby patient-specific anatomical images are overlayed onto intraoperative video and viewed on the laparoscopic screen. Such systems have been demonstrated in laparoscopic adrenalectomy [29] and laparoscopic liver resection [30]. At present the clinical application of this technology is still in its early stages and has the potential to benefit surgeon, patient and trainee in the future.

Digital simulation training has the potential to support surgical trainees in the development of clinical skills outside of the operating theatre. Access to more traditional forms of surgical simulation, such as dry- or wet-lab box trainer simulation training may not be possible for all trainees due to variations in regional training simulation resources [15]. A mobile, digital solution may help to mitigate this problem.

\section{Mobile application simulation}

Mobile applications can provide an opportunity for surgical trainees to enhance their surgical cognitive skills outside the operating theatre, maximising their opportunities in the operating theatre. Mobile applications can provide high-fidelity simulation using computer generated graphics or surgical video. It is possible to enhance the fidelity of simulation using surgical video [31] and provide additional teaching information using graphical overlay to delineate anatomy [32] and additionally provide explanatory labels, annotations and multiple choice questions. New systems are under development validation, and are available for multiple surgical specialities $[32,33]$. There are two platforms that are available for minimally invasive general surgery.

iLapp Surgery ${ }^{\mathrm{TM}}$ is a subscription e-learning platform with modules for training in TaTME and laparoscopic hepatic resections [34]. This system includes a mobile application to support the use of the website. The TaTME modules includes cognitive training in the intraoperative steps with surgical video that can be displaced on the mobile device using Video in Picture. TaTME is a surgical technique that a surgical trainee in the UK and Ireland would be expected to have a level of understanding of, but would not be expected to have performed [6-8].This application may be of interest to trainees with a declared interest in colorectal surgery in their later stages of training, or those in post-CCT fellowship training. Trainees with a declared interest hepatobiliary surgery would be expected to have has exposure performing hepatic resections during their pre-CCT training, and may find this platform useful $[6,7]$. At the time of writing there was no peer-reviewed studies to validate this platform as an educational tool.

Touch Surgery $^{\mathrm{TM}}$ (TS) [17], by Digital Surgery Ltd, is a free, downloadable mobile application which simulates surgery using an interactive, virtual environment on a personal device (phone or tablet). TS uses cognitive task analysis to teach and test knowledge and decision making in the process of surgical procedures. Multiple computergenerated simulations and surgical video simulations are available across all surgical specialties, including index cases, providing content that could be valuable for surgical trainees at all stages of training.

A study of in 51 medical students and 54 surgeons (33 junior trainee, 15 senior trainee, 5 consultants, 1 other) demonstrated face, content and construct validity in TS laparoscopic cholecystectomy modules [35]. In a randomised cross-over study of 52 medical students there was no significant transfer of cognitive skills from TS to a VR laparoscopic skills trainer. However, there was a significant improvement in TS modules scores following VR simulation training, transfer of technical skills was not demonstrated by either group [35].

In a further RCT of medical students attending a laparoscopic skills course, all received the same preparatory didactic teaching and dry-laboratory orientation prior to randomisation to receive either written information on the procedural steps of laparoscopic cholecystectomy or TS laparoscopic cholecystectomy modules [36]. Participants performed a laparoscopic cholecystectomy on a wet-laboratory porcine model, assessed by blinded video analysis using a score modified from a previous study [37]. Chidambaram et al. demonstrate there was an overall improvement in the cognitive performance in students randomised to the TS modules, compared to the control group, with higher overall mean performance score in the group randomised to TS compared to the control group, $41.9 \pm 22.5$ and $24.7 \pm 19.6$, respectively $(\mathrm{p}=0.016)$. Analysis of the cognitive performance of subjects for the steps of laparoscopic cholecystectomy (initial exposure, initial dissection, cystic duct dissection, cystic artery dissection and gallbladder fossa dissection) were all higher in the group randomised to TS, but did not reach statistical significance [36].

\section{Mentored training}

Mentored surgical training has been shown to support trainees at junior and senior levels in gaining surgical skills. Sixteen surgical trainees with limited laparoscopic experience performed a laparoscopic cholecystectomy. Eight consecutive trainees performed their first supervised laparoscopic cholecystectomy without additional coaching, then performed another case within two weeks. Trainers were instructed to provide verbal instruction if 
patient safety was compromised. The subsequent eight consecutive trainees performed their first supervised laparoscopic cholecystectomy followed by a sixty-minute structured coaching session with video playback. Their technical skills were subjectively assessed using video and a validated global assessment scale by blinded assessors. There were no significant differences between the two groups at initial assessment, however the group receiving structured feedback demonstrated significant improvement in the global assessment scale, economy of movement and operative time between their two cases [38].

Surgeons' self-taught proficiency-gain curves for laparoscopic colorectal surgery was considered to be between 150 and 200 cases [39]. A structured, mentored National Training Program, $\left(\right.$ LAPCO $\left.^{\mathrm{TM}}\right)$ was introduced to support UK surgeons to gain proficiency safely and efficiently in laparoscopic colorectal surgery [40]. Fourteen post-CCT trainees' proficiency-gain curves demonstrated selfperceived Global Assessment Score (GAS) competence at 40 cases for mobilisation of the left colon, vascular pedicle division and anastomosis with comparable clinical outcomes to consultants. However, for more complex phases of operation (e.g. mobilisation of the splenic flexure and dissection of the mesorectum) self-perceived GAS competence was not achieved by 40 cases, nor during the study [41]. Risk-adjusted cumulative sum analysis for conversion to an open procedure demonstrated trainees took 24 cases to competently complete the case laparoscopically, under supervision. Of the 608 cases, 9.2\% were converted to open, compared to a conversion rate of $10.6 \%$ reported in the National Bowel Cancer Audit [41]. The study reported an in-hospital mortality of $0.8 \%$ and overall complication rate of $16.9 \%$ and compared their result to meta-analysis data on in-hospital mortality $(0.8 \%)$ and overall complications (18.2\%) [41]. Mackenzie et al. argued colorectal trainees achieved satisfactory outcomes [41]. However, oncological outcomes were not analysed. This study demonstrates trainees with limited laparoscopic skills can be trained in laparoscopic colorectal surgery safely with mentored training. These studies hold some relevance to current colorectal trainees who have a better access to laparoscopic colorectal cases before CCT. It has since been shown that trainees who received mentored laparoscopic colorectal training achieved surgical outcomes comparable with consultants with no significant difference in short- and medium-term oncological outcomes [42]. Table 1 highlights JCST general surgical trainee operative experience requirements and index procedures that can be undertaken laparoscopically. Training benchmarks indicate the stages of training that one would be expected to undertake cases related to special interest training.
Not all surgical trainees have equitable access to mentoring and coaching. Enhancing secure multimedia communication and between trainees and trainers can facilitate learning through discussion and video case review. These interactions can support 1:1 coaching, group learning and peer to peer assessment and support using telementoring.

\section{Telementoring}

AR telementoring in surgery can permit external communication with audio and visual input and telestration (graphical overlay on a live image). This can be established from a disparate site within the hospital or internationally [43, 44]. In a RCT of 19 medical students comparing AR telementoring and traditional mentoring to support dry-lab laparoscopic skills training demonstrated faster skill acquisition in laparoscopic suturing in the intervention group [45]. A study demonstrated the feasibility of telementoring in laparoscopic colorectal surgery and stated that whilst telementored cases took longer, patients had a reduced length of stay and a lymph node yield equivalent to standard cases. However, these results may be influenced by case selection [46]. AR telementoring and telestration technology has evolved, systems such as Proxime ${ }^{\mathrm{TM}}[43,47]$ are now commercially available and allows viewing of live and recorded intraoperative video, telestration and supporting digital data and interactions with other individuals or teams. This could be utilised by trainees and trainers, an integrated surgical command centre or experts in the field, and data could be securely stored for developing technical skill and team performance metrics [47].

\section{Technical skills}

\section{Technical skill influences clinical outcomes}

Surgical errors and poor technical skill in laparoscopic colorectal and UGI surgery are associated with an increased risk of postoperative mortality and morbidity [48-50]. Twenty bariatric surgeons from the United States of America (USA), each submitted a single representative laparoscopic gastric bypass video with clinical data for peer-peer assessment of technical skills. Edited videos were analysed by a minimum of ten peer-raters, and surgeons were allocated to quartiles. Higher surgical skill scores were consistently and significantly correlated with reduced risk-adjusted complication rates and postoperative mortality [50]. In a study of 61 laparoscopic gastrectomy cases unedited videos were analysed using Objective Structured Assessment of Technical Skills (OSATS). A global OSATS score of $\leq 29$, the boundary of low performance, was shown to be an independent predictor of major short-term postoperative outcomes 
(odds ratio 6.49, 95\% confidence interval 1.6-26.39) after adjusting for comorbidity and type of resection [48].

One hundred and seventy-five unedited laparoscopic TaTME videos were analysed using Observational Clinical Human Reliability Analysis (OCHRA) [49]. Curtis et al. argue inconsequential error, or 'near misses' are both prevalent and underreported with greater clinical significance. Patients with higher recorded rates of errors had more early postoperative complications. Cases with a significant intraoperative event demonstrated significantly greater number of 'near misses', compared to cases without significant intraoperative events [49].

\section{Assessing technical skills}

The assessment of surgical technical skills in the UK and Ireland surgical training program is performed with an assessment of clinical skills, as part of a Procedure-Based Assessment (PBA). Trainees are observed by trainers and assigned a criterion-referenced global rating scale from 1 to 4, indicative of competency, where 4 is independent (Table 1). The level of supervision required decreased with time and increased experience, reflected in the global rating scale [51]. PBAs have been shown to be a reliable method of procedure-specific performance in a prospective cohort of motivated trainees and trainers [52]. However, the correct and timely usage of work based assessments is variable, with discrepancies in the perception of delivered and received feedback [53]. Table 1 details the indicative numbers and the global rating level required of trainees at training benchmarks.

In technical skills research total operative time has been used as a surrogate marker of performance. Several tools for the objective assessment of technical skills have been described. Global assessment of surgical skills scores include: GAS [40], PBA [54], OSATS (originally validated for open surgery) [55], Colorectal OSATS [56, 57] Global Operative Assessment of Laparoscopic Skills (GOALS) for laparoscopic skills $[58,59]$ and Structured Assessment of Laparoscopic Assistant Skills (SALAS) for laparoscopic camera navigation [60]. Each assess skills over a number of domains, on 5-point score. The identification and classification of surgical error includes an unnamed score specific to laparoscopic cholecystectomy [37] the Generic Error Rating Tool (GERT) [61] and OCHRA which can be applied to any operation $[49,62$, 63]. Individually these tools have been validated for use in different clinical [63] and educational settings [66], including direct observation and delayed video analysis. Tools for delayed video analysis can be difficult and time consuming to use and are rarely used outside of research or proctored courses, resulting in underutilisation and the valuable insights missed. Recording and reviewing cases for the purposes of operative documentation and education could be of benefit of surgeons, surgical trainees and hospitals $[67,68]$ : a secure, digital solution to automatically store surgical video, with the potential to analyse intraoperative phase times and technical skills would be advantageous by improving access, security and reducing annotation workload [69].

\section{Artificial intelligence and laparoscopic video analysis}

Laparoscopic surgery is dependent on a live video feed, which is infrequently recorded as standard of care. Surgical video is used for education and training [68] and inclusion of surgical video improves the accuracy of intraoperative documentation in laparoscopic colorectal surgery [67]. If appropriately captured, surgical video data could support the development of digital technology. Online surgical communities host video libraries for education and training and offer subscribers the opportunity to view peer-reviewed, edited and narrated cases [70] whilst others offer secure platforms to store and automatically analyse intraoperative times and phases for self and unit evaluation [71] and provide peer-peer assessment of technical skill [72].

Artificial intelligence (AI) networks can be used to extract and analyse visuospatial data in laparoscopic video to classify images in sequence. This technology can identify intraoperative phases and transitions and identify and track laparoscopic tools, which allows interpretation of variability between cases and surgeons. Understanding the surgical workflow allows surgical teams to reveal variability that may have otherwise gone undetected. The surgical workflow can be standardised within or across units or individualised to reflect challenging cases. Supervised learning techniques, whereby AI networks are trained using expert annotation, have been demonstrated to predict the intraoperative phase in laparoscopic cholecystectomy video with an accuracy of $88.9 \% \pm 7.5 \%$ [73], sleeve gastrectomy; $82 \% \pm 4 \%$ videos [74] and laparoscopic left sided colorectal resections; $81 \%$ (no standard deviation reported) [75]. The recognition and tracking of laparoscopic instruments has been achieved [73, 75] and analysing instrument kinematics can enable interpretation of surgical skill [76]. This may support the future development of software to assess surgical skills and identify surgical errors.

The ability of computer systems to 'understand' what is happening in the operating theatre is also known as a 'context-aware' system. This data and analysis can be harnessed to drive digital displays of clinical information such as pre-operative imaging, instruments, learning points and intraoperative steps to provide the surgical team with the information required to both prepare for, to progress and complete the case [77]. Such systems 
have the potential to improve theatre efficiency and surgical training.

\section{Nontechnical skills Team familiarity}

A high turnover of operating theatre staff may contributed unfamiliarity in the operating theatre, In England operating theatre staff increased by $41 \%$ between 2009 and 2018 [78]. Graphical data suggests between October 2018 and March 2019 there were approximately 20,000 and 75,000 advertised full time equivalent vacancies in "medical and dental" and "nursing and midwifery registered" posts, respectively, which could represent a conservative estimate in NHS England, due to the variable definition of vacancy [79]. Staff shortages and agency staff may result in a high turnover of staff in the operating theatre, with many staff working in an unfamiliar environment. Unfamiliarity with the procedure, policy, team and environment [80] was cited as a contributing factor to 'Never Events', which including retained foreign objects, wrong site surgery and wrong implant surgery [80]. Whilst direct causality cannot be implied where a number of systemic failures are present, improving staff 'familiarity' could improve patient safety. Improving the cognitive skills and knowledge of the surgical workflow by accessing digital simulations in advance [32, 35, 36] and utilise AI compatible digital intraoperative workflow could be beneficial for all members of the surgical team in an unfamiliar case and/or environment.

\section{Assessing nontechnical skills}

Lower nontechnical skills scores are associated with observed miscommunications and interruptions across multiple surgical specialties [81]. An observational study in the USA documented observed team behaviours and 30-day post-operative outcomes [82]. Operations with lower frequencies of observed behaviour across the domains "briefing", "information sharing", "inquiry" and "vigilance" over the induction, intraoperative and handoff phases of the operation, were associated with postoperative complications and death, when corrected for comorbidity [82].

Analysis of the surgical team's nontechnical skills was undertaken using synchronized laparoscopic, operating theatre and audio recordings. These recordings were analysed by an expert team to identify safety threats across the domains, external environment, physical environment, organization, tools and technology, tasks and person. One surgeon and their team identified a total of 499 safety threats over 19 cases ( $39.8 \mathrm{~h}$ ) of complex laparoscopic UGI surgery (mean per case $26 \pm$ SD18) and a total of 584 (mean per case $31 \pm$ SD19) resilience supports [83]. Unnecessary conversation during the execution of clinical tasks was a considerable safety threat, which was observed 30 times over 13 cases. Resilience supports included skills coaching, proactive delegation of tasks and consistent execution of the surgical time out [83]. Whilst technical skill and intraoperative errors are documented, a causal relationship between skill and error rate cannot be assumed. This study suggests many errors or 'near misses' were mitigated by nontechnical skills, such as skills coaching, verbalisation of completed tasks and proactive delegation [83]. Definitions of the individual safety threats and resilience supports were not provided. In a randomised control trial of 23 surgical residents comparing standard resident training and standard resident training plus a 2 month nontechnical skills curriculum with didactic and simulation training nontechnical skills were significantly improved in the intervention group as assessed by simulated crisis scenarios [84]. By improving surgeons' nontechnical skills, it could be possible to improve clinical outcomes and improve patient safety.

\section{Team training}

Team training has been shown to reduce operating theatre delays, promote communication and debriefing within the surgical team in a prospective study with a 24 month follow-up period [85]. Simulated operating theatre team training could benefit trainees in the surgical team, a systematic review which included surgical, anaesthetics and emergency medicine trainees team training in simulated crisis management skills demonstrated that trainees' knowledge and nontechnical skills in the simulated environment improved with simulated team training [86].

There is evidence to support diversifying simulated individual and training for both clinical and nontechnical skills. Black box recording systems as described by Kolodzey et al. could provide an integrated digital solution for intraoperative documentation, morbidity and mortality review, supporting positive team interactions and team training.

\section{Discussion}

Efficient training and the assessment of technical and nontechnical skills are key components of surgical training and contribute to a successful procedure. Increasing exposure to video libraries and structured, mentored training at individual and team levels will likely improve the cognitive, technical and nontechnical skills required to perform laparoscopic surgery. It is possible these skills can be transferred to other professional and clinical situations [22, 35, 36, 40, 42, 68, 87].

Enhancing surgical experience in early training, could have a positive effect on the recruitment and retention of doctors into higher surgical training and increase the 
rate of skill acquisition in senior trainees [14]. Training issues and potential digital solutions are summarised in Table 2 and a surgical training timeline is proposed for using these digital solutions in Fig. 1.

The uptake of laparoscopic colorectal surgery has increased and surgical trainees are likely to achieve a greater ratio of laparoscopic to open cases than previously [88]. However, specialist laparoscopic training in the UK and Ireland can be dependent on post-CCT fellowships. Many fellowships will follow the proctored model advocated by $\mathrm{LAPCO}^{\mathrm{TM}}$, and may be taken at "home" or internationally [89]. It is possible that digitally connecting fellows and their trainers with telementoring could enrich the training and mentoring experience. Additionally, international collaboration could foster the consensus and standardization in training. A parallel can be drawn with robotic training. In the UK and Ireland there is currently no agreed or standardized robotic training program for any specialty [90]. Urology, as early adopters of robotic surgery, are an example. There is significant emphasis on pre-clinical simulation training, including model-specific VR simulation and curricula [91] and mentored training [92]. Robotic surgery additionally facilitates easy recording of intraoperative video and the publication of video datasets [93], which has supported the development of AI networks to recognise fine granularity movement of robotic instruments for surgical skills assessment [94]. In the UK and Ireland robotic UGI and colorectal surgery gains popularity, and is successfully being implemented in appropriate centres following mentored training $[95,96]$.

Studies that examine the application of surgical skills assessment scores to laparoscopic videos are often small, single centre observational studies with short follow up and simple mortality outcomes. Whilst these outcomes are of use, limiting outcome data to these parameters does not reflect other important outcomes, such as oncological outcomes or staff and patient acceptability. Neither is it possible to understand the relationship between specific errors or events to particular complications or outcomes [48-50]. Studies also show substantial heterogeneity in design and are likely subject to publication bias [64, 97].

The benefits of developing a digital system include democratising access to training and educational material and efficient and procedural support for surgical teams which can overall improve outcomes and robust, accessible and transparent documentation of intraoperative events. This technology could give further insights into predictions in postoperative morbidity to improve the delivery of care. Digitising a methodology for the assessment of laparoscopic technical skills in everyday practice and delivering structured feedback could improve technical skills. This may also improve the perception of delivered and received feedback, which could improve trainee-trainer relationships. Formalising additional opportunities for technical skills to be constructively assessed and recorded could empower surgeons to record and reflect upon their own progress. This could prompt a surgeon or unit to engage in further training to ensure best practice is achieved and be useful in appraisal and revalidation.

As these systems evolve care should be taken to ensure patient safety is always paramount. Early technology which infers the surgical process may lead to decision support devices, which may be met with trepidation by patients and clinicians alike. It is crucial clinician autonomy remains in the operating theatre. In the future technology that documents surgical team performance may become of increasing importance in cases of litigation and to insurance companies. In our opinion, technology should be used to drive standards higher across the specialty instead of creating new health inequalities.

For these aspirations to be actualized more data is required. Hospitals should consider recording all laparoscopic cases as standard of care, to improve documentation and generate video datasets that can be accessed and analysed retrospectively [67], increasing data accessibility and AI network training [73, 98]. Some hospitals may have difficulty securely storing video data for operative documentation. This is likely to improve as hospitals transition to paperless records.

This review has focussed on laparoscopic surgical training in the UK and Ireland and applied surgical training research and technological developments in Western countries which share similar healthcare systems. It is possible that other healthcare systems may lack some of the required equipment and infrastructure to implement and develop systems applicable to their own healthcare setting. However, the delivery of educational material via personal, portable devices continues to be a viable option as the use of smart phones in developing economies increases $[99,100]$.

\section{Conclusion}

As digital technology continues to develop and support the training of surgical teams we can anticipate a more streamlined and efficient training system that supports the development of cognitive, technical and nontechnical skills simultaneously. Standardising and automating assessments can facilitate trainee progression, maximise the delivery of surgical care and improve outcomes for our patients.

Digital strategies appear to benefit surgeons, surgical teams and patients alike. As these tools develop and are enriched by the growing data available there is the 
Table 2 Summary of key studies demonstrating potential digital solutions to training issues

\begin{tabular}{|c|c|c|c|c|c|}
\hline Training issue & $\begin{array}{l}\text { Potential digital } \\
\text { solution }\end{array}$ & Key studies & Study design & Learner groups & Conclusions \\
\hline \multirow[t]{2}{*}{ Formative experience } & Touch Surgery $^{\text {TM }}$ & $\begin{array}{l}\text { Kowalewski et al. } \\
\text { (2017) [35] }\end{array}$ & $\begin{array}{l}\text { Randomised cross over } \\
\text { study }\end{array}$ & $\begin{array}{l}\text { Medical students } \\
\text { Junior trainee } \\
\text { Senior trainee }\end{array}$ & $\begin{array}{l}\text { Face, content and con- } \\
\text { struct validity of Touch } \\
\text { Surgery } \\
\text { Cognitive skills transfer } \\
\text { more successful with } \\
\text { VR simulation } \\
\text { Valuable training } \\
\text { experience with Touch }^{\text {Surgery }}{ }^{T M}\end{array}$ \\
\hline & Touch Surgery ${ }^{\top M}$ & $\begin{array}{l}\text { Chidambaram et al. } \\
\text { (2019) [36] }\end{array}$ & $\mathrm{RCT}$ & Medical students & $\begin{array}{l}\text { Superior cognitive } \\
\text { performance scores in } \\
\text { Touch Surgery }{ }^{T M} \text { group } \\
\text { compared to control }\end{array}$ \\
\hline $\begin{array}{l}\text { Acquisition of basic } \\
\text { laparoscopic skills }\end{array}$ & VR Simulation & $\begin{array}{l}\text { Nagendran et al. (2013 } \\
\text { [21] }\end{array}$ & $\begin{array}{l}\text { Systematic review } \\
\text { and meta-analysis } \\
\text { of RCTs }\end{array}$ & Surgical trainees & $\begin{array}{l}\text { VR training improves } \\
\text { operative perfor- } \\
\text { mance compared to } \\
\text { box-trainer or no sup- } \\
\text { plementary training }\end{array}$ \\
\hline Operative experience & Video-based education & Ahmet et al. (2018) [68] & $\begin{array}{l}\text { Systematic review of } \\
\text { RCTs }\end{array}$ & $\begin{array}{l}\text { Medical students } \\
\text { Surgical trainees }\end{array}$ & $\begin{array}{l}\text { Video-based education } \\
\text { associated with higher } \\
\text { performance score and } \\
\text { trainee satisfaction }\end{array}$ \\
\hline \multirow[t]{2}{*}{ Constructive feedback } & $\begin{array}{l}\text { Coaching with video } \\
\text { analysis }\end{array}$ & $\begin{array}{l}\text { Grantcharov et al. } \\
\text { (2007) [38] }\end{array}$ & Interventional study & 2 surgical trainees & $\begin{array}{l}\text { Constructive coaching } \\
\text { with video analysis } \\
\text { improved global } \\
\text { assessment score }\end{array}$ \\
\hline & $\begin{array}{l}\text { Coaching with VR } \\
\text { Simulation }\end{array}$ & Cole et al. (2014) [22] & $\mathrm{RCT}$ & Junior trainees & $\begin{array}{l}\text { Reduction in errors and } \\
\text { improvement of CAT } \\
\text { over time with addi- } \\
\text { tional coaching }\end{array}$ \\
\hline \multirow[t]{6}{*}{ Assessment of skill } & Peer review of video & $\begin{array}{l}\text { Birkmeyer et al.(2013) } \\
\text { [50] }\end{array}$ & $\begin{array}{l}\text { Observational/feasi- } \\
\text { bility }\end{array}$ & Surgeons & $\begin{array}{l}\text { Poor technical skills asso- } \\
\text { ciated with postopera- } \\
\text { tive complication } \\
\text { Peer assessment of video } \\
\text { successful }\end{array}$ \\
\hline & $\begin{array}{l}\text { Automated video } \\
\text { assessment }\end{array}$ & $\begin{array}{l}\text { Twinanda et al. (2017) } \\
\text { [73] }\end{array}$ & Experimental & Surgeons & $\begin{array}{l}\text { Accurate phase predic- } \\
\text { tion and instrument } \\
\text { recognition in laparo- } \\
\text { scopic cholecystec- } \\
\text { tomy }\end{array}$ \\
\hline & $\begin{array}{l}\text { Automated video } \\
\text { assessment }\end{array}$ & $\begin{array}{l}\text { Hashimoto et al. (2019) } \\
\text { [74] }\end{array}$ & Experimental & Surgeons & $\begin{array}{l}\text { Accurate phase predic- } \\
\text { tion and instru- } \\
\text { ment recognition in } \\
\text { laparoscopic sleeve } \\
\text { gastrectomy video }\end{array}$ \\
\hline & $\begin{array}{l}\text { Automated video } \\
\text { assessment }\end{array}$ & Jin et al. (2018) [76] & Experimental & Surgeons & $\begin{array}{l}\text { Instrument tracking } \\
\text { suitable for inferring } \\
\text { laparoscopic skills in } \\
\text { laparoscopic cholecys- } \\
\text { tectomy video }\end{array}$ \\
\hline & $\begin{array}{l}\text { Automated video } \\
\text { assessment }\end{array}$ & $\begin{array}{l}\text { Kitaguchi et al. (2020) } \\
\text { [75] }\end{array}$ & Experimental & Surgeons & $\begin{array}{l}\text { Accurate phase predic- } \\
\text { tion and instrument } \\
\text { recognition in laparo- } \\
\text { scopic left sided-colo- } \\
\text { rectal resection video }\end{array}$ \\
\hline & $\begin{array}{l}\text { Automated live video } \\
\text { assessment }\end{array}$ & $\begin{array}{l}\text { Winter Beaty et al. } \\
\text { (2019) [52] }\end{array}$ & Experimental & Surgeons & $\begin{array}{l}\text { Accurate phase predic- } \\
\text { tion and in laparo- } \\
\text { scopic sleeve gastrec- } \\
\text { tomy live video }\end{array}$ \\
\hline
\end{tabular}


Table 2 (continued)

\begin{tabular}{|c|c|c|c|c|c|}
\hline Training issue & $\begin{array}{l}\text { Potential digital } \\
\text { solution }\end{array}$ & Key studies & Study design & Learner groups & Conclusions \\
\hline $\begin{array}{l}\text { Supporting independ- } \\
\text { ent operating }\end{array}$ & AR and Tele-surgery & $\begin{array}{l}\text { Greenfield et al. (2018) } \\
\text { [43] }\end{array}$ & Case Study & Surgeons & $\begin{array}{l}\text { Successful international } \\
\text { audio-visual communi- } \\
\text { cation with interactive } \\
\text { graphical overlay }\end{array}$ \\
\hline Surgical skill acquisition & $\begin{array}{l}\text { AR telemontoring and } \\
\text { simulated skills }\end{array}$ & Vera et al. (2014) [45] & $\mathrm{RCT}$ & Medical students & $\begin{array}{l}\text { Faster skill acquisition in } \\
\text { simulation with AR tel- } \\
\text { ementoring mentoring }\end{array}$ \\
\hline \multirow[t]{2}{*}{ Surgical teamwork } & Black box analysis & $\begin{array}{l}\text { Kolodzey et al.(2019) } \\
\text { [83] }\end{array}$ & Observational & Single surgeon & $\begin{array}{l}\text { Surgical "near misses' } \\
\text { prevented by non- } \\
\text { technical skills }\end{array}$ \\
\hline & Tele-surgery & Lin et al. (2020) (44) & Feasibility & Orthopaedic surgeons & $\begin{array}{l}\text { Live streaming and } \\
\text { tele-mentoring during } \\
\text { arthroscopy }\end{array}$ \\
\hline
\end{tabular}

$A R$ augmented reality, VR virtual reality, CAT Competency Assessment Tool



Fig. 1 A suggested timeline for digital support in general surgical training

possibility to provide widespread access to high quality training materials and assessment. In the future this could lead to standardised, regulated systems that can support surgical teams in providing safer surgical care.

\section{Abbreviations}

Al: Artificial intelligence; AR: Augmented reality; CAT: Competency Assessment Tool; COSATS: Colorectal Objective Structured Assessment of Technical Skills; CCT: Certificate of completion of training; EWTD: European Working Time Directive; GAS: Global Assessment Score; GERT: Generic Error Rating Tool; GOALS: Global Operative Assessment of Laparoscopic Skills; JCST: Joint Committee on Surgical Training; NHS: National Health Service; OCHRA: Observational Clinical Human Reliability Assessment; OSATS: Objective Structured Assessment of Technical Skills; PBA: Procedure Based Assessment; RCT: Randomized Control Trial; SALAS: Structured Assessment of Laparoscopic Assistant
Skills; SHO: Senior House Officer; TaTME: Transanal total mesorectal excision of the rectum; TS: Touch surgery ${ }^{\text {TM }}$; UGI: Upper gastrointestinal; UK: United Kingdom; USA: United States of America; VR: Virtual reality.

\section{Acknowledgements}

Not applicable.

\section{Authors' contributions}

$\mathrm{GH}$ was responsible for the conceptualization of the review. GH performed the literature search, drafted, revised and edited the manuscript. RH, DS and LBL revised and edited the manuscript. All authors read and approved the final manuscript.

\section{Authors information}

GH is a general surgery trainee and a Clinical Training Fellow at the Wellcome/ EPSRC Centre for Interventional and Surgical Sciences, University College London, UK and studying for a PhD. GH is currently Past President of the Association of Surgeons in Training. 
$\mathrm{RH}$ is a Consultant Colorectal Surgeon at Swansea Bay University Health Board $\mathrm{RH}$ is also Director, and previous Past President, of the Association of Surgeons in Training.

DS is Director of the Wellcome/EPSRC Centre for Interventional and Surgical Sciences, University College London and Professor of Robot Vision at the Department of Computer Science at University College London. DS is also Chief Scientist at Digital Surgery Ltd.

LBL is Clinical Director of the Wellcome/EPSRC Centre for Interventional and Surgical Sciences, University College London and Professor of Gastroenterology and Biophotonics at the Division of Surgery and Interventional Sciences at University College London.

\section{Funding}

This work is supported by The National Institute for Health Research University College London (UCL) Hospitals, Biomedical Research Centre, Digital Surgery Ltd $^{\text {TM }}$, Cancer Research UK Experimental Cancer Medicine Centre at UCL and the Wellcome/EPSRC Centre for Interventional and Surgical Sciences at UCL. Funders have had no influence on this work.

\section{Availability of data and materials}

Not applicable.

\section{Declarations}

\section{Ethics approval and consent to participate}

Not applicable.

\section{Consent for publication}

Not applicable.

\section{Competing interests}

GH's salary is paid via an educational grant from Digital Surgery Ltd to University College London Hospitals NHS Foundation Trust. RH has no competing interests to declare. DS is an employee of Digital Surgery Ltd. LBL has no competing interests to declare.

\section{Author details}

${ }^{1}$ Wellcome/EPSRC Centre for Interventional and Surgical Sciences, University College London, Charles Bell House, 43-45 Foley Street, London W1W 7TY, UK. ${ }^{2}$ Division of Surgery and Interventional Science, University College London, London, UK. ${ }^{3}$ Swansea Bay University Health Board, Swansea, Wales, UK.

${ }^{4}$ Department of Computer Science, University College London, London, UK.

Received: 16 December 2020 Accepted: 25 February 2021

Published online: 08 March 2021

\section{References}

1. NHS. The NHS Long Term Plan. 2019. https://www.longtermplan.nhs. uk/wp-content/uploads/2019/08/nhs-long-term-plan-version-1.2.pdf.

2. Corbridge R, O'Loughlin M, Rooney L, McGovern M. Health in the Digital Society | Digital Society for Health DHSS Task Force 4-Digital Transformation. 2018. https://www.ehealthireland.ie/News-Media/ News-Archive/2017/Task-Force-pdf-update.pdf/.

3. National Audit Office. Digital transformation in the NHS-Summary. 2020. https://www.nao.org.uk/wp-content/uploads/2019/05/Digit al-transformation-in-the-NHS.pdf.

4. Topol E. Preparing the healthcare workforce to deliver the digital future The Topol Review an independent report on behalf of the Secretary of State for Health and Social Care. 2019;(February):102. https://topol.hee. nhs.uk/wp-content/uploads/HEE-Topol-Review-2019.pdf.

5. Royal College of Surgeons of England. Future of surgery. 2018. https:// futureofsurgery.rcseng.ac.uk/.

6. Joint Committee on Surgical Training. Certification Guidelines for General Surgery. 2017. https://www.jcst.org/quality-assurance/certificat ion-guidelines-and-checklists/.
7. Intercollegiate Surgical Curriculum Program. The Intercollegiate Surgical Curriculum Educating the surgeons of the future General Surgery. 2017. https://www.iscp.ac.uk/static/public/syllabus/syllabus_gs_2016.pdf.

8. Intercollegiate Surgical Curriculum Program. General Surgery Curriculum 2021. 2020. https://www.iscp.ac.uk/media/1103/general-surge ry-curriculum-aug-2021-approved-oct-20v3.pdf.

9. Intercollegiate Surgical Curriculum Program. Core Surgical Training Curriculum 2021. 2020. https://www.iscp.ac.uk/media/1103/general-surge ry-curriculum-aug-2021-approved-oct-20v3.pdf.

10. Lund J. The new General Surgical Curriculum and ISCP. Surg (United Kingdom). 2020;38(10):601-6. https://doi.org/10.1016/j.mpsur .2020.07.005.

11. Bates T, Cecil E, Greene I. The effect of the EWTD on training in general surgery: an analysis of electronic logbook records. Ann R Coll Surg Engl. 2007;89(3):106-9. https://doi.org/10.1308/147363507X177045.

12. Thomas R, Karanjia N. Comparison of $\mathrm{SHO}$ surgical logbooks a generation apart. Ann R Coll Surg Engl. 2009;91(10):356-9. https://doi. org/10.1308/147363509X475781.

13. Breen KJ, Hogan AM, Mealy K. The detrimental impact of the implementation of the European working time directive (EWTD) on surgical senior house officer (SHO) operative experience. Ir J Med Sci. 2013;182(3):383-7. https://doi.org/10.1007/s11845-012-0894-6.

14. Glasbey JC, Harries RL, Beamish AJ, Gokani VJ, Mohan H, Williams AP, et al. Early years postgraduate surgical training programmes in the UK are failing to meet national quality standards: An analysis from the ASiT/ BOTA Lost Tribe prospective cohort study of 2,569 surgical trainees. Int J Surg. 2018;52(August 2017):376-82. https://www.sciencedirect.com/ science/article/pii/S1743919117313274?via\%3Dihub.

15. Nicholas R, Humm G, Macleod KE, Bathla S, Horgan A, Nally DM, et al. Simulation in surgical training: Prospective cohort study of access, attitudes and experiences of surgical trainees in the UK and Ireland. Int J Surg. 2019;67:94-100. https://doi.org/10.1016/j.ijsu.2019.04.004.

16. Mirriam-Webster. Virtual reality. https://www.merriam-webster.com/ dictionary/virtualreality.

17. TouchSurgeryTM. TouchSurgeryTM. 2020. https://www.touchsurge ry.com/simulations.

18. 3D Systems. LapMentorTM. 2020. https://simbionix.com/simulators/ lap-mentor/.

19. FundamentalVR. HapticVRTM. 2020. https://www.fundamentalvr. com/\#hapticvr.

20. FundamentalVR. Mixed Reality. 2020. https://www.fundamentalvr. com/\#mixedreality.

21. Nagendran M, Gurusamy K, Aggarwal R, Loizidou M, Davidson BR. Virtual reality training for surgical trainees in laparoscopic surgery. Cochrane Database Syst Rev. 2013;(8). https://www.cochranelibrary. com/cdsr/doi/https://doi.org/10.1002/14651858.CD006575.pub3/full.

22. Cole SJ, Miskovic D, Hanna GB, Ha J, Mackenzie H. Randomized controlled trial on the effect of coaching in simulated laparoscopic training. Surg Endosc. 2014;28(3):979-86. https://link.springer.com/artic le/10.1007\%2Fs00464-013-3265-0.

23. Milgram P, Kishino F. A taxonomy of mixed reallity visual displays. 1994;E77-D(12):1-15. https://www.researchgate.net/publication/23151 4051_A_Taxonomy_of_Mixed_Reality_Visual_Displays.

24. Devoto L, Muscroft S, Chand M. Highly accurate patient-specific 3D mixed reality model creation for surgical training and decision-making. JAMA Surg. 2019;In Press. https://jamanetwork.com/journals/jamas urgery/article-abstract/2748068.

25. Kwak JM, Romagnolo L, Wijsmuller A, Gonzalez C, Agnus V, Lucchesi FR, et al. Stereotactic pelvic navigation with augmented reality for transanal total mesorectal excision. Dis Colon Rectum. 2019;62(1):123-9. https ://journals.Iww.com/dcrjournal/Abstract/2019/01000/Stereotactic_Pelvi c_Navigation_With_Augmented.20.aspx.

26. Huber T, Hadzijusufovic E, Hansen C, Paschold M, Lang H, Kneist W. Head-mounted mixed-reality technology during robotic-assisted transanal total mesorectal excision. Dis Colon Rectum. 2019;62(2):25861. https://journals.Iww.com/dcrjournal/Abstract/2019/02000/Head_ Mounted_Mixed_Reality_Technology_During.21.aspx.

27. Ishioka J, Kihara K, Higuchi S, Nakayama T, Takeshita H, Yoshida S, et al. New head-mounted display system applied to endoscopic management of upper urinary tract carcinomas. Int Braz J Urol. 
2014;40(6):842-5. http://www.brazjurol.com.br/november_decem ber_2014/Ishioka_842_845.pdf.

28. Al Janabi HF, Aydin A, Palaneer S, Macchione N, Al-Jabir A, Khan MS, et al. Effectiveness of the HoloLens mixed-reality headset in minimally invasive surgery: a simulation-based feasibility study. Surg Endosc. 2019. https://doi.org/10.1007/s00464-019-06862-3.

29. Marescaux J, Rubino F, Arenas M, Mutter D, Soler L. Augmented-realityassisted laparoscopic adrenalectomy. JAMA. 2004;292:2214-5. https:// jamanetwork.com/journals/jama/article-abstract/199759.

30. Thompson S, Schneider C, Bosi M, Gurusamy K, Ourselin S, Davidson B, et al. In vivo estimation of target registration errors during augmented reality laparoscopic surgery. Int J Comput Assist Radiol Surg. 2018;13(6):865-74. https://doi.org/10.1007/s11548-018-1761-3.

31. Luengo I, Flouty E, Giataganas P, Wisanuvej P, Nehme J, Stoyanov D. SurReal: enhancing surgical simulation realism using style transfer. 2018;1-12. http://arxiv.org/abs/1811.02946.

32. Knol J, Keller DS. Cognitive skills training in digital era: a paradigm shift in surgical education using the TaTME model. Surg. 2018 Apr 30; http:// www.ncbi.nlm.nih.gov/pubmed/29724664.

33. Naveed $H$, Hudson R, Khatib M, Bello F. Basic skin surgery interactive simulation: system description and randomised educational trial. https://doi.org/https://doi.org/10.1186/s41077-018-0074-5.

34. iLappSurgery Foundation. iLappSurgery. http://www.lappsurge ry.com/.

35. Kowalewski KF, Hendrie JD, Schmidt MW, Proctor T, Paul S, Garrow CR, et al. Validation of the mobile serious game application Touch SurgerYTM for cognitive training and assessment of laparoscopic cholecystectomy. Surg Endosc. 2017;31(10):4058-66. https://link.springer.com/artic le/10.1007\%2Fs00464-017-5452-x.

36. Chidambaram S, Erridge S, Leff D, Purkayastha S. A randomized controlled trial of skills transfer: from touch surgery to laparoscopic cholecystectomy. J Surg Res. 2019;234(0):217-23. https://www.journ alofsurgicalresearch.com/article/S0022-4804(18)30663-2/fulltext.

37. Eubanks TR, Clements RH, Pohl D, Williams N, Schaad DC, Horgan S, et al. An objective scoring system for laparoscopic cholecystectomy. 1999. https://www.sciencedirect.com/science/article/pii/S107275159 9002185.

38. Grantcharov TP, Schulze S, Kristiansen VB. The impact of objective assessment and constructive feedback on improvement of laparoscopic performance in the operating room. Surg Endosc Other Interv Tech. 2007 Dec;21(12):2240-3. https://link.springer.com/article/https:// doi.org/10.1007/s00464-007-9356-z.

39. Tekkis PP, Senagore AJ, Delaney CP, Fazio VW. Evaluation of the learning curve in laparoscopic colorectal surgery: Comparison of right-sided and left-sided resections. Ann Surg. 2005;242(1):83-91. https://insights.ovid. $\mathrm{com} /$ pubmed?pmid $=15973105$.

40. Coleman MG, Hanna GB, Kennedy R. The National Training Programme for Laparoscopic Colorectal Surgery in England: a new training paradigm. Color Dis. 2011 Jun;13(6):614-6. http://doi.wiley.com/https://doi. org/10.1111/j.1463-1318.2011.02643.x.

41. Mackenzie H, Miskovic D, Ni M, Parvaiz A, Acheson AG, Jenkins JT, et al. Clinical and educational proficiency gain of supervised laparoscopic colorectal surgical trainees. Surg Endosc. 2013;27(8):2704-11. https:// link.springer.com/article/https://doi.org/10.1007/s00464-013-2806-X.

42. De'Ath HD, Devoto L, Mehta C, Bromilow J, Qureshi T. Mentored trainees have similar short-term outcomes to a consultant trainer following laparoscopic colorectal resection. World J Surg. 2017;41(7):1896-902. https://link.springer.com/article/https://doi.org/10.1007/s0026 8-017-3925-7.

43. Greenfield M, Luck J, Billingsley M, Heyes R, Smith O, Mosahebi A, et al. Demonstration of the effectiveness ofaugmented reality telesurgery in complex hand reconstruction in Gaza. Plast Reconstr Surg Glob Open. 2018;21(6(3)):e1708. www.PRSGlobalOpen.com.

44. Lin C-C, Chen Y-P, Chiang C-C, Chang M-C, Lee OK-S. Real-Time Streaming of Surgery Performance and Intraoperative Imaging Data in the Hybrid Operating Room: Development and Usability Study. JMIR Med Informatics. 2020;8(4):e18094. https://medinform.jmir.org/2020/4/ e18094/.

45. Vera AM, Russo M, Mohsin A, Tsuda S. Augmented reality telementoring (ART) platform: a randomized controlled trial to assess the efficacy of a new surgical education technology. Surg Endosc. 2014;28(12):3467-72. https://doi.org/10.1007/s00464-014-3625-4.

46. Schlachta CM, Kent SA, Lefebvre KL, McCune ML, Jayaraman S. A model for longitudinal mentoring and telementoring of laparoscopic colon surgery. Surg Endosc. 2009;23(7):1634-8. https://doi.org/10.1007/s0046 4-008-0221-5.

47. Karim JS, Hachach-Haram N, Dasgupta P. Bolstering the surgical response to COVID-19: how virtual technology will save lives and safeguard surgical practice. BJU Int. 2020;125(6):E18-9. https://doi. org/10.1111/bju.15080.

48. Fecso AB, Bhatti JA, Stotland PK, Quereshy FA, Grantcharov TP. Technical performance as a predictor of clinical outcomes in laparoscopic gastric cancer surgery. Ann Surg. 2019;270(1):115-20. https://journals.Iww. com/annalsofsurgery/Abstract/2019/07000/Technical_Performance_ as_a_Predictor_of_Clinical.20.aspx\#: :text=Thepresent study showed that,major short-term postoperative complications.

49. Curtis NJ, Dennison G, Brown CSB, Hewett PJ, Hanna GB, Stevenson ARL, et al. Clinical evaluation of intraoperative near misses in laparoscopic rectal cancer surgery. Ann Surg. 2019;XX(XX):1. https://journals.Iww. com/annalsofsurgery/Abstract/9000/Clinical_Evaluation_of_Intraopera tive_Near_Misses.95052.aspx.

50. Birkmeyer JD, Finks JF, O'reilly A, Oerline M, Carlin AM, Nunn AR, et al. surgical skill and complication rates after bariatric surgery abstract. N Engl J Med. 2013;369:1434-76. https://doi.org/10.1056/NEJMsa1300 625.

51. Elsey EJ, Griffiths G, West J, Humes DJ. Changing autonomy in operative experience through UK general surgery training: a national cohort study. Ann Surg. 2019;269(3):399-406.

52. Marriott J, Purdie H, Crossley J, Beard JD. Evaluation of procedure-based assessment for assessing trainees'skills in the operating theatre. $\mathrm{Br} J$ Surg. 2011;98(3):450-7. https://doi.org/10.1002/bjs.7342.

53. Gaunt A, Patel A, Royle J, Fallis S, Almond M, Mylvaganam S, et al. What do surgeons and trainees think of WBAs and how do they use them? Bull R Coll Surg Engl. 2016;98(9):408-14. https://publishing.rcseng ac.uk/doi/full/https://doi.org/10.1308/rcsbull.2016.408?trendmd-share $d=1$.

54. Marriott J, Purdie H, Crossley J, Beard JD. Evaluation of procedure-based assessment for assessing trainees skills in the operating theatre. $\mathrm{Br}$ 」 Surg. 2011;98(3):450-7. https://doi.org/10.1002/bjs.7342.

55. Martin JA, Regehr G, Reznick R, Macrae H, Murnaghan J, Hutchison C, et al. Objective structured assessment of technical skill (OSATS) for surgical residents. Br J Surg. 1997;84(2):273-8. https:// bjssjournals.onlinelibrary.wiley.com/doi/abs/https://doi.org/10.104 6/j.1365-2168.1997.02502.x?sid=nlm\%3Apubmed.

56. De Montbrun SL, Roberts PL, Lowry AC, Ault GT, Burnstein MJ, Cataldo $\mathrm{PA}$, et al. A novel approach to assessing technical competence of colorectal surgery residents: the development and evaluation of the colorectal objective structured assessment of technical skill (COSATS). Ann Surg. 2013;258(6):1001-6.

57. De Montbrun S, Roberts PL, Satterthwaite L, Macrae H. Implementing and evaluating a national certification technical skills examination. Ann Surg. 2016;264(1):1-6.

58. Vassiliou MC, Feldman LS, Andrew CG, Bergman S, Leffondré K, Stanbridge $D$, et al. A global assessment tool for evaluation of intraoperative laparoscopic skills. Am J Surg. 2005;190(1):107-13.

59. Chang L, Hogle NJ, Moore BB, Graham MJ, Sinanan MN, Bailey R, et al. Reliable assessment of laparoscopic performance in the operating room using videotape analysis. Surg Innov. 2007;14(2):122-6. https:// doi.org/10.1177/1553350607301742.

60. Huber T, Paschold M, Schneble F, Poplawski A, Huettl F, Watzka F, et al. Structured assessment of laparoscopic camera navigation skills: the SALAS score. Surg Endosc. 2018;32(12):4980-4. https://doi.org/10.1007/ s00464-018-6260-7.

61. Bonrath EM, Zevin B, Dedy NJ, Grantcharov TP. Error rating tool to identify and analyse technical errors and events in laparoscopic surgery. $\mathrm{Br} J$ Surg. 2013:100(8):1080-8. https://doi.org/10.1002/bjs.9168.

62. Joice P, Hanna GB, Cuschieri A. Errors enacted during endoscopic surgery — a human reliability analysis. Appl Ergon. 1998;29(6):409-14. https://www.sciencedirect.com/science/article/abs/pii/S000368709 8000167?via\%3Dihub. 
63. Tang B, Hanna GB, Joice P, Cuschieri A. Identification and categorization of technical errors by Observational Clinical Human Reliability Assessment (OCHRA) during laparoscopic cholecystectomy. Arch Surg. 2004;139(11):1215-20. https://jamanetwork.com/journals/jamasurgery/ fullarticle/397547.

64. Foster JD, Francis NK. Objective assessment of technique in laparoscopic colorectal surgery: what are the existing tools? Tech Coloproctol. 2015;19(1):1-4. https://doi.org/10.1007/s10151-014-1242-9.

65. Curtis NJ, Davids J, Foster JD, Francis NK. Objective assessment of minimally invasive total mesorectal excision performance: a systematic review. Tech Coloproctol. 2017;21(4):259-68. https://doi.org/10.1007/s1015 1-017-1614-z.

66. Tang B, Hanna GB, Cuschieri A. Analysis of errors enacted by surgical trainees during skills training courses. Surgery. 2005;138(1):14-20.

67. Van De GraafFW, Lange MM, Spakman J, Van Grevenstein WMU, Lips D, De Graaf EJR, et al. Comparison of systematic video documentation with narrative operative report in colorectal cancer surgery. JAMA Surg. 2019;154(5):381-9. https://jamanetwork.com/journals/jamasurgery/ fullarticle/https://doi.org/10.1001/jamasurg.2018.5246.

68. Ahmet A, Gamze K, Rustem M, Sezen KA. Is video-based education an effective method in surgical education? A systematic review. J Surg Educ. 2018;75(5):1150-8. https://doi.org/10.1016/j.jsurg.2018.01.014.

69. TouchSurgeryTM. TouchSurgery EnterpriseTM. https://www.touchsurge ry.com/enterprise.

70. IRCAD. Websurg. https://websurg.com/en/

71. TouchSurgeryTM. TouchSurgery ProfessionalTM. 2020. https://www. touchsurgery.com/professional.

72. C-SATS. C-SATS. 2020. https://www.csats.com/.

73. Twinanda AP, Shehata S, Mutter D, Marescaux J, De Mathelin M, Padoy N. EndoNet: a deep architecture for recognition tasks on laparoscopic videos. IEEE Trans Med Imaging. 2017;36(1):86-97. https://arxiv.org/ abs/1602.03012

74. Hashimoto DA, Rosman G, Witkowski ER, Stafford C, Navarette-Welton AJ, Rattner DW, et al. Computer vision analysis of intraoperative video. Ann Surg. 2019;270(3):414-21. https://journals.Iww.com/annalsofsurgery/Abstr act/2019/09000/Computer_Vision_Analysis_of_Intraoperative_Video 3.aspx.

75. Kitaguchi D, Takeshita N, Matsuzaki H, Oda T, Watanabe M, Mori K, et al. Automated laparoscopic colorectal surgery workflow recognition using artificial intelligence: experimental research. Int J Surg. 2020;79(March):8894. https://www.sciencedirect.com/science/article/pii/S17439191203039 88.

76. Jin A, Yeung S, Jopling J, Krause J, Azagury D, Milstein A, et al. Tool detection and operative skill assessment in surgical videos using region-based convolutional neural networks. Proc 2018 IEEE Winter Conf Appl Comput Vision, WACV 2018. 2018;2018-Janua:691-9. https://arxiv.org/ abs/1802.08774

77. Winter Beatty J, Kerr K, Luengo I, Giataganas P, Stoyanov D, Kinross J, et al. Intelligent operating room. In: SAGES 2019 Annual Meeting 3-5 April 2019. Baltimore, Maryland, USA. https://www.sages.org/meetings/annua I-meeting/abstracts-archive/intelligent-operating-room/.

78. NuffieldTrust.TheNHSworkforce in numbers. https://www.nuffieldtrust.org uk/resource/the-nhs-workforce-in-numbers\#1-what-kinds-of-staff-makeup-the-nhs-workforce.

79. NHS Digital. NHS Vacancy Statistics; England, February 2015-March 2019. 2015;(February 2015). https://digital.nhs.uk/data-and-information/publi cations/statistical/nhs-vacancies-survey/nhs-vacancy-statistics-englandmarch-2014-to-february-2015-provisional-experimental-statistics.

80. NHS Improvement. Surgical never events. Learning from 38 cases occurring in English hospitals between April 2016 and March 2017. 2018;(September):1-93. https://improvement.nhs.uk/documents/3213/Learning_from_ surgical_Never_Events_FINAL.pdf.

81. Gillespie BM, Harbeck E, Kang E, Steel C, Fairweather N, Chaboyer W. Correlates of non-technical skills in surgery: a prospective study. BMJ Open. 2017;7(1):1-9. https://bmjopen.bmj.com/content/7/1/e014480.

82. Mazzocco K, Petitti DB, Fong KT, Bonacum D, Brookey J, Graham S, et al. Surgical team behaviors and patient outcomes. Am J Surg. 2009;197(5):678-85.

83. Kolodzey L, Trbovich P, Kashfi A, Grantcharov TP. System factors affecting intraoperative risk and resilience. Ann Surg. 2019; XX(XX):1. https:// insights.ovid.com/pubmed?pmid=30946083.
84. Dedy NJ, Bonrath EM, Ahmed N, Grantcharov TP. Structured training to improve nontechnical performance of junior surgical residents in the operating room: a randomized controlled trial. Ann Surg. 2016;263(1):43-9. https://journals.Iww.com/annalsofsurgery/Abstr act/2016/01000/Structured_Training_to_Improve_Nontechnical.8.aspx.

85. Wolf FA, Way LW, Stewart L. The efficacy of medical team training: improved team performance and decreased operating room delays: a detailed analysis of 4863 cases. Ann Surg. 2010;252(3):477-83. https:// insights.ovid.com/pubmed?pmid $=20739848$.

86. Doumouras AG, Keshet I, Nathens AB, Ahmed N, Hicks CM. A crisis of faith? A review of simulation in teaching team-based, crisis management skills to surgical trainees. J Surg Educ. 2012; http://www.bemec ollaboration.org.

87. Dijkstra FA, Bosker RJI, Veeger NJGM, van Det MJ, Pierre JPEN, Beerthuizen $\mathrm{G}$, et al. Procedural key steps in laparoscopic colorectal surgery, consensus through Delphi methodology. Surg Endosc. 2015;29:2620-7. https://doi.org/10.1007/s00464-014-3979-7.

88. Hanna GB, Mackenzie H, Miskovic D, Ni M, Wyles S, Aylin P, et al. Laparoscopic colorectal surgery outcomes improved after national training program (LAPCO) for specialists in England. Ann Surg. 2020;Publish Ah. https://journals.Iww.com/annalsofsurgery/Abstract/9000/Laparoscop ic_Colorectal_Surgery_Outcomes_Improved.94080.aspx.

89. Fleming C, Pucher P, Elsey E, Glasbey J, Conneely J, Hogan A, et al. Structure and quality assurance of Fellowship Training in General Surgery: Consensus recommendations from the Association of Surgeons in Training. Int J Surg. 2019;67(December 2018):101-6. https://www.sciencedirect.com/ science/article/pii/S1743919119300561?via\%3Dihub.

90. Dixon F, Keeler B. Robotic surgery: training, competence assessment and credentialing. Bull R Coll Surg Engl. 2020;102(7):302-6. https://publishing. rcseng.ac.uk/doi/full/https://doi.org/10.1308/rcsbull.2020.185.

91. Stegemann AP, Ahmed K, Syed JR, Rehman S, Ghani K, Autorino R, et al. Fundamental skills of robotic surgery: a multi-institutional randomized controlled trial for validation of a simulation-based curriculum. Urology. 2013;81(4):767-74. https://doi.org/10.1016/j.urology.2012.12.033.

92. Wang RS, Ambani SN. Robotic surgery training current trends and future directions. Urol Clin North Am. 2021. https://doi.org/10.1016/j. ucl.2020.09.014.

93. Haro BB, Khudanpur S, Ahmidi N, Gao Y, Tao L, Vidal R, et al. A dataset and benchmarks for segmentation and recognition of gestures in robotic surgery. IEEE Trans Biomed Eng. 2017;64(9):2025-41. http://ieeexplore.ieee. org/document/7805258/.

94. Funke I, Mees ST, Weitz J, Speidel S, et al. Video-based surgical skill assessment using 3D convolutional neural networks. Int J Comput Assist Radiol Surg. 2019. https://doi.org/10.1007/s11548-019-01995-1.

95. Thomas A, Altaf K, Sochorova D, Gur U, Parvaiz A, Ahmed S. Effective implementation and adaptation of structured robotic colorectal programme in a busy tertiary unit. J Robot Surg. 2020. https://doi.org/10.1007/s1170 1-020-01169-1.

96. Bellorin O, Vigiola-Cruz M, Dimou F, At R, Al Hussein Alawamlh O, Pomp A, et al. Robotic-assisted surgery enhances the learning curve while maintaining quality outcomes in sleeve gastrectomy: a preliminary, multicenter study. Surg Endosc. 2021. https://doi.org/10.1007/s00464-020-08228-6.

97. Curtis NJ, Davids J, Foster JD, Francis NK. Objective assessment of minimally invasive total mesorectal excision performance: a systematic review. Tech Coloproctol. 2017. https://doi.org/10.1007/s10151-017-1614-z.

98. Maier-Hein L, Wagner M, Ross T, Reinke A, Bodenstedt S, Full PM, et al. Heidelberg colorectal data set for surgical data science in the sensor operating room. https://arxiv.org/abs/2005.03501.

99. Silver L, Simth A, Johnson C, Taylor K, Jiang J, Anderson M, et al. Mobile connectivity in emerging economies. Pew Res Cent. 2019;(March):93. https://www.pewinternet.org/2019/03/07/mobile-connectivity-inemerging-economies/.

100. Bunogerane GJ, Taylor K, Lin Y, Costas-Chavarri A. Using touch surgery to improve surgical education in low- and middle-income settings: a randomized control trial. J Surg Educ. 2018;75(1):231-7. https://doi. org/10.1016/j.jsurg.2017.06.016.

\section{Publisher's Note}

Springer Nature remains neutral with regard to jurisdictional claims in published maps and institutional affiliations. 